\title{
Pulmonary rehabilitation at a time of social distancing: prime time for tele- rehabilitation?
}

\author{
Linzy Houchen-Wolloff, ${ }^{1,2}$ Michael C Steiner (1) 1,2
}

The global COVID-19 pandemic and the concomitant social distancing measures taken in many countries to suppress transmission of the virus has had an immediate and profound effect on the provision of pulmonary rehabilitation (PR) services. Conventional PR programmes organised around groups of people attending a rehabilitation centre have been suspended in most affected countries to ensure vulnerable people are effectively shielded from the virus. However, the need for PR has not gone away and consideration is under way about how best to provide effective therapy in the context of the current crisis. ${ }^{12}$ The issue of enhancing access to effective PR is not a new one. The overwhelming evidence for the effectiveness of the intervention (reducing disability, improving quality of life $^{3}$ and potentially offering a survival advantage for those who complete the programme ${ }^{4}$ ) has been tempered by well-documented problems across many healthcare systems in ensuring PR is accessible for all who need it. ${ }^{5}$ It is this problem that has taken centre stage in the field in recent years, and the need for innovation in the delivery of PR is a clear and urgent challenge in the context of the current pandemic.

Helpfully, in the linked article, Hansen and colleagues report the results of a randomised controlled trial comparing home-based tele-rehabilitation with conventional centre-based PR in a population with severe COPD. ${ }^{6}$ Participants in the experimental arm of the study were provided with a touchscreen videoconferencing device together with basic home exercise equipment (dumbbells and a one-step box). PR sessions were provided by video conference in groups of up to eight participants over a period of 10 weeks. Importantly, the system was extremely easy to use, with patient cancellations due

${ }^{1}$ Centre for Exercise and Rehabilitation Science (CERS), NIHR Leicester Biomedical Research Centre Respiratory, Glenfield Hospital, Leicester, UK ${ }^{2}$ Department of Respiratory Science, University of Leicester, Leicester, UK

Correspondence to Dr Linzy Houchen-Wolloff, Pulmonary Rehabilitation, University Hospitals of Leicester, Leicester LE5 4PW, UK;

linzy.houchen@uhl-tr.nhs.uk to technical problems occurring in only 12 of 1902 connections - an important issue because previous studies have highlighted problems with web literacy in people eligible for PR. ${ }^{78}$ Patients allocated to the control arm attended conventional supervised group PR sessions in groups of 6-12 over 10-12 weeks.

The authors hypothesised that telerehabilitation would be superior to conventional PR because adherence to PR sessions would be greater. In fact, they observed no between-group difference in the primary endpoint ( 6 min walk distance) or indeed secondary outcomes including respiratory symptoms, quality of life, physical activity and lower-limb muscle function. Importantly, although completion rates were notionally better in the tele-rehabilitation arm, adherence to PR (judged by attendance at PR sessions) was not different between the groups. The authors can be congratulated on undertaking a rigorous, scientifically robust trial of an important service delivery methodology for PR. What do the results of this trial and other recent investigations tell us about how such an innovation might perform in practice?

In addition to indicating that the home teleconferencing format did not enhance adherence, the reported recruitment rates suggest it might not enhance uptake of an offer of PR as two-thirds of those approached declined participation in the trial because they wanted to attend conventional centre-based PR. This provides an illustration of the difficulties in testing the effectiveness of extending choice of PR delivery format through trials involving randomisation at the patient level. Participants are required a priori to be able to undertake either format, and the first action in taking part in a trial is the removal of choice through random assignment. Although increments in exercise performance observed by Hansen et al were significant (but not different between groups), the magnitude was smaller than expected, raising concerns that the study population was not representative or the interventions were not sufficiently intense or individualised. Inferences on the relative efficacy of the two interventions are limited because the trial was insufficiently powered to determine equivalence and exercise modes and volumes were inevitably different between the groups.

Previous studies comparing remotely supported PR conducted in patients' home environment have suggested the benefits were non-inferior to conventional centrebased PR..$^{9-13}$ In some, similar to the study by Hansen et al, ${ }^{6}$ increments in exercise performance following the intervention were lower in the conventional PR arm $^{9} 1012$ compared with those observed in routine clinical practice. ${ }^{14}$ Field walking performance is potentially less subject to a placebo effect in trials than measures of health status and therefore might offer useful insight on the degree to which the results of such trials can be generalised and the degree to which participants are representative of the general PR population. In interpreting these individual trials, the devil is often in the detail surrounding the intensity of the intervention, eligibility criteria for participants, statistical methodology (intention to treat vs per-protocol comparisons) and relative dropout rates which are frequently different between study groups. ${ }^{10} 13$ Other studies have suggested that tele-rehabilitation approaches can be complementary to conventional centre-based interventions, for example as a means to maintain the benefits of $\mathrm{PR}^{15}$ or for those unable or unwilling to participate in the standard offering. ${ }^{16}$

It is self-evident that extending the choice of programme delivery available to patients will be helpful to PR practitioners and referrers who have a key role in encouraging participation. It is very unlikely that one format will prove superior to others as patients will have a variety of support needs based on individual factors, such as self-efficacy, activation, education level and disease severity. Testing these approaches may require cluster designs with randomisation/comparison made at a programme rather than a patient level. The most important consideration in evaluating such innovations in PR delivery is ensuring that improvements in uptake and adherence to PR are achieved without sacrificing the efficacy of the intervention. Therapeutic efficacy can be gauged by assessing service outcomes in the context of an audit/quality improvement framework such as that provided in the UK by the National Asthma and COPD Audit Programme (https://www.rcplondon.ac. $\mathrm{uk} /$ projects/national-asthma-and-copdaudit-programme-nacap). In this model, key quality control (clinical outcome) and assurance (process) benchmarks 
are identified nationally, and individual programmes submit performance metrics that are measured against these benchmarks. Outlier policies can identify programmes where innovations are being tested whose outcomes fall outside the accepted limits. In this way trade-offs between accessibility and effectiveness can be understood and information provided to $\mathrm{PR}$ practitioners to help patients make informed choices.

The longer term impact of the COVID-19 pandemic on provision of service to people with chronic respiratory disease is uncertain but could well be significant. The requirement for rapid deployment of alternative means of maintaining patient contact and communication is likely to inform and change services in the future. Similarly, we can expect patients to exercise more caution about attending face-to-face or group activities because of heightened awareness of crossinfection risks, which may exacerbate already low levels of PR uptake. The PR community is ready to innovate to solve this problem, but as the linked trial highlights we will need to be watchful that the value of the intervention is not diluted.

Twitter Linzy Houchen-Wolloff @LinzyWolloff

Contributors Both authors contributed equally to the drafting of the manuscript.

Funding The authors have not declared a specific grant for this research from any funding agency in the public, commercial or not-for-profit sectors.

Competing interests None declared.

Patient consent for publication Not required.

Provenance and peer review Commissioned; externally peer reviewed.

This article is made freely available for use in accordance with BMJ's website terms and conditions for the duration of the covid-19 pandemic or until otherwise determined by BMJ. You may use, download and print the article for any lawful, non-commercial purpose (including text and data mining) provided that all copyright notices and trade marks are retained.

(C) Author(s) (or their employer(s)) 2020. No commercial re-use. See rights and permissions. Published by BMJ.

\section{A Check for updates}

To cite Houchen-Wolloff L, Steiner MC. Thorax 2020;75:446-447.

Accepted 24 April 2020

Published Online First 12 May 2020

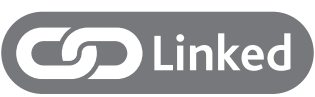

- https://doi.org/10.1136/thoraxjnl-2019-214246

Thorax 2020;75:446-447.

doi:10.1136/thoraxjnl-2020-214788

\section{ORCID iD}

Michael C Steiner http://orcid.org/0000-0002-01270614

\section{REFERENCES}

1 Gardiner L. Resource pack for pulmonary rehabilitation, 2020. Available: https://www.britthoracic.org.uk/about-us/covid-19-information-for-therespiratory-communityl

2 Spruit M. Report of an AD hoc international Task force to develop an expert-based opinion on early and short-term rehabilitative interventions (after the acute hospital setting) in COVID 19 survivors, 2020. Available: https://ers.app.box.com/s/npzkvigt/4w3pb0v bsth4y0fxe7ae9z9

3 McCarthy B. Pulmonary rehabilitation for chronic obstructive pulmonary disease. Cochrane Database Syst Rev 2015;23:CD003793.

4 Houchen-Wolloff L, Williams JE, Green RH, et al. Survival following pulmonary rehabilitation in patients with COPD: the effect of program completion and change in incremental shuttle walking test distance. Int I Chron Obstruct Pulmon Dis 2018;13:37-44.

5 Rochester CL, Vogiatzis I, Holland AE, et al. An official American thoracic Society/European respiratory Society policy statement: enhancing implementation, use, and delivery of pulmonary rehabilitation. Am I Respir Crit Care Med 2015;192:1373-86.
6 Hansen H, Bieler T, Beyer N, et al. Supervised pulmonary tele-rehabilitation versus pulmonary rehabilitation in severe COPD: a randomised multicentre trial. Thorax 2020;75:421.

7 Gibb M, Willott V, Lohar S, et al. P48 An evaluation to understand the use of technology within a COPD population. Thorax 2013;68:A96.2-7.

8 Houchen-Wolloff L. Feasibility of a web-based selfmanagement programme, as a 'bridge' to starting pulmonary rehabilitation, for individuals hospitalised with an acute exacerbation of chronic obstructive pulmonary disease (AECOPD). Thorax 2018;73:A8-9.

9 Bourne S, DeVos R, North M, et al. Online versus face-to-face pulmonary rehabilitation for patients with chronic obstructive pulmonary disease: randomised controlled trial. BMJ Open 2017;7:e014580.

10 Holland AE, Mahal A, Hill CJ, et al. Home-Based rehabilitation for COPD using minimal resources: a randomised, controlled equivalence trial. Thorax 2017;72:57-65.

11 Horton EJ, Mitchell KE, Johnson-Warrington V, et al. Comparison of a structured home-based rehabilitation programme with conventional supervised pulmonary rehabilitation: a randomised non-inferiority trial. Thorax 2018;73:29-36

12 Casey D, Murphy K, Devane D, et al. The effectiveness of a structured education pulmonary rehabilitation programme for improving the health status of people with moderate and severe chronic obstructive pulmonary disease in primary care: the Prince cluster randomised trial. Thorax 2013;68:922-8.

13 Chaplin E, Hewitt S, Apps L, et al. Interactive web-based pulmonary rehabilitation programme: a randomised controlled feasibility trial. BMJ Open 2017;7:e013682.

14 Steiner M. Pulmonary rehabilitation: beyond breathing better. National chronic obstructive pulmonary disease (COPD) audit programme: outcomes from the clinical audit of pulmonary rehabilitation services in England 2015, 2017. Available: https://www.rcplondon.ac.uk/ projects/outputs/pulmonary-rehabilitation-beyondbreathing-better

15 Vasilopoulou M, Papaioannou Al, Kaltsakas G, et al. Home-Based maintenance tele-rehabilitation reduces the risk for acute exacerbations of COPD, hospitalisations and emergency department visits. Eur Respir J 2017:49:1602129.

16 Houchen-Wolloff L, Gardiner N, Devi R, et al. Web-based cardiac REhabilitatioN alternative for those declining or dropping out of conventional rehabilitation: results of the WREN feasibility randomised controlled trial. Open Heart 2018;5:e00860. 